Nadwa : Jurnal Pendidikan Islam

Vol. 12, Nomor 1 Tahun 2018

Accredited by Ristekdikti based on Decree No. 51/E/KPT/2017

\title{
Fenomenologi Hukuman di Pesantren : Analisis Tata Tertib Santri Pondok Pesantren Daruttaqwa Gresik
}

\author{
Muhammad Anas Ma`arif \\ Institut Pesantren KH Abdul Chalim Mojokerto \\ anasmaarif@ikhac.ac.id; anasdt16@gmail,com \\ Ari Kartiko \\ Institut Pesantren KH Abdul Chalim Mojokerto \\ ari.kartiko5@gmail.com
}

\begin{abstract}
This study aims to identify and describe the pattern of punishment in Daruttaqwa Gresik Pesantren. This research method uses phenomenological study about the meaning and value of punishment given to santri. The findings of the study indicate that First, the pattern of punishment for the offenders of discipline is with, reprimand and advice, administrative punishment, educational punishment, social punishment, material punishment, physical punishment. Secondly, there are rules for educators who will apply the punishment that is not in a hurry, should not hit when in a state of anger, should avoid sensitive limbs and do not hit the child in under 10 years. Third, in the students is instilled the consciousness in the santri that punishment given to him is a just and educational punishment. By conditioning the three elements above, then punishment will be effective in educating children.

Keywords: punishment; Islamic education; teacher rules; pesantren;.
\end{abstract}

\begin{abstract}
Abstrak
Penelitian ini bertujuan untuk mengidentifikasi dan mendeskripsikan pola hukuman di Pesantren Daruttaqwa Gresik. Metode penelitian ini menggunakan studi fenomenologis tentang makna dan nilai hukuman yang diberikan kepada santri. Temuan penelitian menunjukkan bahwa satu, pola pemberian hukuman bagi pelanggar tata tertib santri adalah dengan, teguran dan nasehat, hukuman administrasi, hukuman yang mendidik, hukuman bersifat sosial, hukuman materi, hukuman bersifat fisik. Kedua, Terdapat aturan bagi pendidik yang akan menerapkan hukuman antara lain : tidak terburu-buru, tidak boleh memukul ketika dalam keadaan marah, hendaknya menghindari anggota badan yang peka, dan tidak memukul anak di bawah 10 tahun.. Ketiga, pada diri anak didik ditanamkan kesadaran dalam diri santri bahwa hukuman yang diberikan kepadanya merupakan hukuman yang adil dan mendidik. Dengan mengkondisikan tiga elemen diatas, maka hukuman akan efektif dalam mendidik anak.
\end{abstract}

Kata Kunci : hukuman; pendidikan Islam; aturan guru; pesantren; 


\section{Pendahuluan}

Manusia merupakan mahluk yang diberi kelebihan oleh Tuhan Yang Maha Kuasa di bandingkan dengan makhluk yang lainnya di muka bumi ini, yaitu dengan diberikanya akal manusia yang bisa membedakan sesuatu yang baik dan sesuatu yang buruk. Dengan memiliki akal bisa menjadikan manusia mempunyai kuaitas yang tinggi1.

Salah satu wahana untuk meningkatkan sumber daya manusia adalah dengan pendidikan karena pendidikan merupakan sarana untuk membangun watak bangsa. (Nation Character Building)2. Oleh sebab itu pendidikan harus di tingkatkan bukan hanya pada kurikulum atau satu komponen saja akan tetapi semua komponen pendidikan harus saling menguatkan 3 . Sehingga tujuan pendidikan bisa tercapai yaitu insan kamil. 4

Komponen penting yang sering menjadi perdebatan adalah motode dan alat pendidikan yaitu hukuman. Metode ini didasarkan atas fitrah (sifat kejiwaan) manusia, yaitu sifat

1 Imam Suprayogo, Pengembangan pendidikan karakter (Malang: UIN Maliki Press, 2013), 8-9.

2 Pendidikan di sini dapat didifinisikan menurut dua aspek. Pertama dari sudut pandang individu, dan kedua dari fenomena sosial. Dari sudut pandang individu pendidikan berarti pengembangan potensi-potensi yang terpendam sehingga mampu berkembang seoptimal mungkin. Dalam konteks ini pendidikan lebih berorientasi internal berupa pengembangan potensi dasar insaniah. Adapun sebagai fenomena sosial pendidikan dimaknai sebagai proses kulturasi (pembudayaan), yakni sosialisasi (pemasyarakatan) nilainilai, ilmu pengetahuan dan ketrampilan yang berkembang di masyarakat. Dalam konteks ini lebih berorientasi eksternal dalam kerangka perkembangan budaya masyarakat, sehingga dalam realitas kehidupannya manusia mampu berinteraksi dengan lingkungan sekitarnya. Baharuddin, Moh Makin, dan Abdul Qodir Shaleh, Pendidikan humanistik (konsep, teori, dan aplikasi praksis dalam dunia pendidikan) (Yogyakarta: Ar-Ruzz Media, 2007), 20.

3 Mujamil Qomar, Kesadaran Pendidikan, Sebuah Penentu Keberhasilan Pendidikan (Yogyakarta: Ar-Ruzz Media, 2012), 15.

4 Ahmad Tafsir, Ilmu pendidikan dalam perspektif Islam, Cet. 1 (Bandung: Remaja Rosdakarya, 1992), 63; Ramayulis dan Samsul Nizar, Filsafat pendidikan Islam: telaah sistem pendidikan dan pemikiran para tokohnya (Jakarta: Kalam Mulia, 2009), 118. 
keinginan pada kesenangan, keselamatan dan tidak menginginkan kesengsaraan dan kepedihan.5

Dibeberapa Negara, hukuman dalam pendidikan dilarang secara explisit akan tetapi dalam prakteknya pendidik selalu menggunakan hukuman sebagai alat untuk mendisiplinkan peserta didik6. Meskipun dipahami bahwa hukuman diberikan karena ada pelanggaran dengan tujuan untuk mendisiplinkan7, tetapi banyak pendidik dan orang tua masih menggunakan hukuman seperti menegur anak agar terhindar dari kejelekan8 dengan tujuan sebagai vaksinasi dini dalam konteks pendidikan pun layak diberikan bagi mereka yang bermasalah. 9

Pada dasarnya beberapa dari pendidik masih banyak yang tidak bisa membedakan hukuman dan kekerasan sehingga dalam pendidikan sering dijumpai adanya pendidik yang menghukum peserta didik yang mengarah pada kekerasan 10. Hukuman harus diberikan sesuai dengan tingkat kesalahnya11 dan sesuai dengan prosedur aturan yang berlaku. Sehingga hukuman bisa mengurangi perilaku yang ganjil pada anak 12. Hukuman sangat

5 Ahmad Tafsir, Ilmu pendidikan Islami, Cet. 1 (Bandung: Remaja Rosdakarya, 2012), 218.

6 Negara Amerika, India, Korea Selatan, Taiwan, China dan Israel melarang pendidiknya untuk menggunakan alat pendidikan dengan hukuman, akan tetapi pada prakteknya pendidik masih menggunakan hukuman sebagai alat/metode untuk mendisiplinkan peserta didik mereka. Wong Pakil, "Corporal Punishment of Students by Teachers in Elementary and Middle Schools in Taiwan the Relationship with School Level, Gender, School Location, Academic Performance and Emotional Reactions." (University of Southern California, 2011), 25-34; Amerika dan 24 negara bagian masih menggunakan hukuman Lihat. Santrock John W, Psikologi Pendidikan, 2 ed., 6 (Jakarta: Prenada Media Grup, 2015), 283.

7 Ramayulis dan Nizar, Filsafat pendidikan Islam, 256.

8 Martyn Long, ed., The Psychology of Education, 2nd ed (London; New York: Routledge, 2011), 352.

9 Fajar Malik, Holistika Pemikiran Pendidikan (Jakarta: Raja Grafindo Persada, 2005), 201.

10 M. Djamal, Fenomena Kekerasan di Sekolah (Yogyakarta: Pustaka Pelajar, 2016), 21.

11 Bagheri Naorapast Khosrow, Pendidikan Islam, Wacana Alternatif, trans. oleh Ety Triana (Jakarta: Citra, 2016), 178.

12 B. R Hergenhahn dan Matthew H Olson, Theories of learning = teori belajar, trans. oleh Triwibowo, 6 ed. (Jakarta: Prenada Media Grup, 2016), 98. 
perlu diberikan guna memberikan efek jera kepada para santri sehingga mereka tidak akan mengulangi perbuatan yang sama di kemudian hari13.

Pesantren merupakan suatu komunitas tersendiri, dimana kyai ustadz santri dan pengurus pesantren hidup bersama satu kampus berlandaskan nilai-nilai Islam dengan norma-norma dan tradisi yang di asuh oleh kyai 14. Nurcholis Madjid menyebut pesantren dengan istilah indegeneous culture (pendidikan asli Indonesia) 15, yang tumbuh sejak awal kedatangan Islam Indonesia16.

Pesantren terdiri dari beberapa unsur yaitu, asrama, kyai, masjid, santri, kitab kuning, sedangkan elemen paling esensial pesantren adalah kyai 17. Sebagai pengasuh santri-santri yang mempunyai karismatik sehingga santri banyak yang patuh dan takzim dengan tujuan mendapat berkah 18 .

Meski rawan menimbulkan kekerasan, hukuman tetap dipandang efektif sebagai salah satu sarana penegakan disiplin santri. Apalagi terdapat teks-teks baik dalam al-Qur'an maupun Hadis yang secara eksplisit membolehkan pemberian hukuman dalam pelaksanaan pendidikan, meskipun dalam bentuk pemukulan. Bagaimana memahami konsep tarhib (hukuman) dalam pendidikan Islam? Pertanyaan ini merupakan persoalan yang perlu dicari jawabannya. Oleh karenanya penelitian tentang pemberian hukuman dalam kaitannya dengan sanksi-sanksi

13 Nawangsari Dyah, "Pemberian Hukuman Dalam Pendidikan Islam (Studi Makna Sanksi-Sanksi Pelanggaran Kode Etik Santri Di Pondok Pesantren Assunniyah Kencong Jember)" (UIN Sunan Ampel Surabaya, 2013), 4 .

14 Mastuhu, Dinamika sistem pendidikan pesantren: suatu kajian tentang unsur dan nilai sistem pendidikan pesantren, 2 ed. (Jakarta: INIS, 1994), 57.

15 Madjid Nurcholis, Bilik-Bilik Pesantren Sebuah Potret Perjalanan, 6 ed. (Jakarta: Paramadina Grup, 2016), 17.

16 Zamakhsyari Dhofier, Tradisi pesantren: studi pandangan hidup kyai dan visinya mengenai masa depan Indonesia, Cet. 8 rev (Jakarta: LP3ES, 2011), 38 .

17 Dhofier, 93.

18 Karisma kyai didasarkan kekuatan spiritual dan kemampuan memberi berkah karena hubunganya dengan alam gaib. Van Bruinessen Martin, Kutab Kuning Pesantren dan Tarekat, 1 ed. (Yogyakarta: Gading Publising, 2012), 88. 
pelanggaran tata tertib di pondok pesantren menjadi penting untuk dilakukan.

Dengan pendekatan kualitatif dirasa tepat untuk mengakomodir masalah tersebut19. Oleh karenanya penelitian kualitatif lebih mementingkan perspektif emik, dan bergerak dari fakta, informasi atau peristiwa menuju ke tingkat abstraksi yang lebih tinggi (apakah konsep atau teori) 20

\section{Pesantren}

Sejarah pesantren menurut Ridlwan Nasir adalah lembaga pendidikan Islam yang tertua di Indonesia. Keberadaan pesantren dengan segala aspek kehidupan dan perjuanganya ternyata memiliki nilai strategis dalam membina manusia yang berkualitas iman, ilmu dan amal21. Pesantren sesungguhnya memiliki tiga peran dan fungsi sesuai dengan watak kemandirian dan visinya yaitu: pertama, sebagai lembaga pendidikan dan pengembangan ajaran Islam dengan mencetak sumber daya manusia yang handal dan reproduksi ulama`. Kedua, lembaga perjuangan dan dakwah islamiyah. Ketiga. Sebagai lembaga pengembangan dan pengabdian masyarakat.22

Pesantren adalah lembaga pendidikan tradisonal Islam untuk memahami, menghayati, dan mengamalkan ajaran agam Islam (tafaqquh fiddin) dengan menekankan pentingnya moral agama Islam sebagai pedoman bermasyarakat sehari-hari. Penyelenggaraan lembaga pendidikan pesantren berbentuk asrama yang merupakan komunitas tersendiri dibawa kiai atau

19 Penelitian yang bersifat alamiah seperti ini tepatnya menggunakan pendekatan desain kualitatif (qualitative design). Penelitian kualitatif sendiri didifinisikan sebagai prosedur penelitian yang menghasilkan data diskriptif berupa kata-kata tertulis atau lisan orang-orang dan perilaku yang diamati. Pendekatan ini diarahkan pada latar dan individu tersebut secara holistik (utuh). Lihat Robert Bogdan dan Sari Knopp Biklen, Qualitative research for education: an introduction to theory and methods, 3rd ed (Boston: Allyn and Bacon, 1998), 322.

20 Kuswarno Engkus, Metodelogi Penelitian Komunikasi, Fenomenologi, Konsepsi dan Pedoman (Bandung: Widya Padjadjaran, 2009), 126.

21 Nasir Ridlwan, Mencari Tipologi Format Pendidikan Ideal di Tengah Arus Perubahan, 2 ed. (Jakarta: Pustaka Pelajar, 2010), 83.

22 Zaprulkan, Ilmu Tasawuf Sebuah Kajian Tematik (Jakarta: Raja Grafindo Persada, 2006), 224. 
ulama` dibantu seorang atau beberapa orang ulama`serta ustadz yang hidup bersama ditengah para santri dengan masjid, sebagai pusat pengajaran dan pendidikan dan pondok-pondok atau asrama sebagai tempat tinggal santri selama 24 jam 23.

Dari beberapa unsur pesantren kyai merupakan elemen paling esensisal dari suatu pesantren. Kyai merupakan pendiri pesantren sudah sewajarnya bahwa pertumbuhan pesantren semata-mata bergantung dari kemampuan kyai 24. Kyai sering dapat membangun peran strategisnya sebagai pimpinan masyarakat yang nonformal melalui suatu komunikasi yang intensif dengan penduduk25. Kepemimpinan kyai dapat berpola karismatik, maksudnya adalah suatu pola kepemimpinan yang mengacu pada suatu figur sentral yang dianggap oleh komunitas penduduknya memiliki kekuatan supranatural dari Allah, kelebihan dalam berbagai bidang keilmuan dan mekanisme kepemimpinan tidak diatur secara birokratik26. Begitupun yang terjadi pada KH. Muhammad Munawwar Kholil (wafat 2012) yang merupakan pendiri pondok pesantren Daruttaqwa Gresik. Karisma beliau tidak diragukan lagi dikarenakan memiliki pengaruh yang cukup besar di gresik surabaya dan sekitarnya.

Kharisma itu terletak pada kecakapan beliau dalam menggerakkan masa untuk bekerja sama. Ini dilihat dari banyaknya masyarakat yang datang ke kyai untuk meminta "barakah" doa agar dikabulkan permintaannya kepada Allah. Dengan demikian kyai dianggap memilki karamah yang dapat berperan sebagai perantara yang bisa menggabungkan dunia manusia eksotris dan dunia supranatural esoteris. Tidak bisa dupungkiri bahwa ada kebersinggungan pesantren dengan faham sufi, sehingga tidak heran faham tersebut cukup berpengaruh dalam kehidupan pesantren. pada kenyataanya kemunculan pesantren pada awal abad ke 20 sebagai lembaga pendidikan yang mandiri kebanyakan bercorak tarekat.

23 Mastuhu, Dinamika sistem pendidikan pesantren, 6 .

24 Dhofier, Tradisi pesantren, 93.

${ }_{25}$ Ziemek Manfred, Pesantren Dalam Perubahan Sosial (Jakarta: P3M, 1983), 138.

26 Ridlwan, Format Pendidikan Ideal, 23. 
Pesantren Daruttaqwa Gresik merupakan pesantren yang berafiliasi ke arah tarekat walaupun $\mathrm{KH}$ Munawwar tidak menjadi mursyidnya. Beliau adalah murid KH. Ustman Al-Ishaqi Surabaya yang wafat tahun 1984 yang mana KH Ustman merupakan murid KH Romly Tamim (pendiri tarekat Qodiriyah Nahsabandiyah Jombang).27 Karena keuletan dan kesabaran KH Munawwar Khalil selaku pendiri pesantren Daruttaqwa yang berdiri hingga saat ini. KH. Munawwar tekenal sebagai seorang yang sabar, ahli ibadah, ahli tasawuf, ahli fiqih, serta seorang yang visioner dalam mengembangkan madrasah dan pesantrenya. Keahlian beliau tidak hanya sebatas ucapan belaka akan tetapi dibuktikan dengan beberapa kitab tulisan beliau seperti. Faidul Illah fi Fadli Dzikru Allah, Auliya'ul falihin 3 jilid, Tasfiyatul Qulub, Badrul Alam, Naf ul amim 4 jilid sarah Minhajul Qowin yang belum selesai karena beliau wafat. Sepeninggal KH. Munawar Khalil wafat tahun 201228, tongkat estafet diberikan kepada beberapa putra beliau dan yang menjadi pengasuh utama saat ini adalah KH. Ainul Muttaqien yaitu menantu beliau.

Dalam diri santri juga ditananmkan bahwa mereka adalah orang-orang yang menyerahkan dan menitipkan hidupnya kepada Kyai yang sangat dihormati dan disegani. Santri diajarkan diibaratkan seorang yang buta sehingga memerlukan bantuan sang Kyai atau murshid29 yang ma'rifat billah. Santri diajarkan untuk patuh dan taat kepada gurunya serta harus mensucikan hati melalui beberapa perbuatan agar bisa menjalankan ibadah secara benar dan taqwa serta muroqobah pada Allah.

Melakukan kedisiplinan tidak hanya sebatas melakukan amal ibadah kepada Allah tetapi juga keseharian dipesantren. Hal ini butuhkan tata tertib (segala yang mengatur apa yang seharusnya

27 Van Bruinessen Martin, Tarekat Naqsabandiyah DI Indonesia, 1 ed. (Bandung: Mizan, 1992), 95.

28 Kedudukan kyai tidak bisa diwariskan begitu saja oleh keturunanya, dan wafatnya kyai biasanya menandai berakirnya sebuah kepemimpinan kharismatik. Horikoshi Hiroko, Kyai dan Perubahan Sosial, trans. oleh Basalim Umar (Jakarta: P3M, 1987), 212.

${ }_{29}$ Orang yang dipandang mampu dan tahu cara mendekatkan diri kepada Allah, pemimpin bagi suatu tarekat dan membimbing murid-muridnya Zaprulkan, Ilmu Tasawuf, 99. 
dilakukan dan tidak boleh dilakukan 30) agar santri tersebut menjaga perilaku yang diharapkan oleh pesantren dan masyarakat. Dikarenakan disiplin merupakan salah satu cara agar peserta didik/santri bisa mencapai tujuanya.

\section{Bentuk Hukuman di Pesantren}

Tata tertib adalah salah satu tindakan preventif pada santri agar tidak melakukan tindakan diluar batas. Meskipun tata tertib pesantren sudah ada akan tetapi tidak sedikit beberapa santri melakukan tindakan buruk dengan melanggar tata tertib tersebut. Oleh sebab itu dibutuhkan hukuman represif31 agar peserta didik ini tidak mengulangi kesalahan yang sama.

Ada beragam pemberian hukuman bagi pelanggar tata tertib santri yaitu dengan,

1. Teguran dan nasehat,

Sanksi diberikan pada santri yang melanggar tata tertib pesantren tidak langsung diberikan hukuman melainkan dilihat seberapa besar kesalahan yang diperbuat. Jika santri melakukan kesalahan yang pertama dalam melanggar tata tertib pesantren dikategorikan ringan tindakan yang dilakukan adalah teguran. Dan teguran ini efektif di berikan segera setelah perilaku tersebut terjadiz2.

2. Hukuman yang mendidik dan hukuman administrasi,

Ketika teguran dan nasehat tidak bisa menjadikan santri berbuat baik malah melakukan pelanggaran berkali-kali maka santri akan diberikan hukuman yang mendidik misalkan, membaca sholawat didepan rumah kyai, membaca manaqib beberapa jam, membaca nadhaman dan lain lain. Hukuman mendidik ini biasanya dibaregi dengan hukuman administrasi yaitu memberitahukan pelanggaran yang dilakukan oleh santri kepada wali santrinya

3. Hukuman bersifat sosial,

30 M. Djamal, Fenomena Kekerasan, 16.

31 Hukuman yang dilakukan karena ada pelanggaran yang dilakukan Purwanto Ngalim, Ilmu Pendidikan Teoritis dan Praktis, 17 ed. (Bandung: Remaja Rosdakarya, 2006), 189.

32 John W, Psikologi Pendidikan, 282. 
Santri yang melakukan pelanggaran tata tertib pada tingkat sedang seperti, tidak mengikuti sekolah diniah berulang kali, pulang ke rumah tanpa seizin pengurus pesantren dan pengasuh, merokok di area pesantren dan lain sebagainya akan diberikan sanksi berupa hukuman bersifat sosial yaitu membersihkan halaman pesantren, membersihkan kamar mandi pesantren, membersihkan parit-parit pesantren dan sebagainya.

4. Hukuman materi, Sanksi pelanggaran tata tertib juga bisa bersifat materi seperti menyumbang pesantren dengan membelikan semen dan lain lain.

5. Hukuman bersifat fisik.

Alternative terakir dalam memberikan sanksi di pesantren Daruttaqwa Gresik adalah hukuman fisik, coorporan punishment. Misalkan santri di pukul betisnya, santri di gundul, dijemur di depan pesantren. Pelanggaran yang dilakukan santri adalah bisanya mencuri, pulang tanpa izin, merokok di area pesantren. Santri tidak langsung diberikan sanksi akan tetapi diberi pilihan untuk memilih hukuman dikarenakan santri bisanya tidak mau diberikan hukuman secara sosial dan hukuman secara materi maka mereka lebih memilih hukuman secara fisik. Sanksi yang terakir juga diberikan apabila santri melakukan pelanggaran tata tertib paling berat seperti santri melakukan tindakan amoral, melakukan perlakukan menyimpang melanggar nilai-nilai agama seperti berzinah, mabuk-mabukan, mencuri dan sebagainya. Hukuman ini diberikan oleh pengasuh berupa keluar dari pesantren.

Dari urutan hukuman tersebut hukuman fisik adalah cara yang paling akhir diberikan pada pelanggaran santri dan sifatnya paling berat. 


\section{Aplikasi Hukuman di Pesantren}

Santri dianggap seperti anak sendiri untuk menyanyangi dan di didik sepertianak sendiri 33 sehingga hukuman dilakukan dengan niat untuk merubah perilaku santri yang kurang baik untuk menjadi lebih baik. Pendidik menganggap bahwa santri adalah fitrah manusia.34 Santri membutuhkan seorang penjaga dan membimbing agar tidak salah dalam menjalankan kehidupan sehai-hari. Misalkan santri melanggar tata tertib tidak melakukan shalat jamaah 3 kali berturut-turut maka pendidik akan memberikan hukuman dengan maksud mencegah perbuatan tersebut terulang dan menjadi karakter kurang baik bagi diri santri. Rasulallah memberikan saran bagi pendidik agar memberikan hukuman mendidik kepada anak yang tidak mau melakukan salat dan agar setiap anak termotivasi untuk melakukan shalat. Abu Dawud dan Hakim meriwayatkan dari Amr bin Syu aib dari ayahnya, dari kakeknya bahwa Rasul Saw bersabda: 35

$$
\text { ورو أبناء عسر وفر بالصلاة وهم أبناء سبع سنين واضربو هم عليها }
$$

Artinya: suruhlah anak-anak kalian mengejakan shalat sejak mereka berusia tujuh tahun. Pukullah mereka jika mereka melalaikanya. Yaitu ketika mereka berumur 10 tahun dan pisahkan tempat tidur mereka".

Di samping adanya dalil yang membolehkan pemberian hukuman bahkan dalam bentuk fisik sekalipun, pemberian hukuman yang dilakukan oleh santri juga di dorong oleh rasa hormat kepada guru dan pengasuh pesantren Daruttaqwa. Rasa hormat ini ditanamkan sejak dini kepada santri sebagai bentuk akhlak santri kepada gurunya. Penanaman ini dilakukan melalui pengajaran beberapa kitab tasawuf seperti kitab Ihya'Ulum AdDin karya Imam Al-Ghazali, kitab Risalatul Qusahiriyah karya Imam Qusyairi, bahkan kitab karangan pendiri pesantren

33 Abu Muhammad Iqbal, Pemikiran pendidikan Islam: gagasangagasan besar para ilmuwan Muslim, Cetakan 1 (Yogyakarta: Pustaka Pelajar, 2015), 96.

34 Tafsir, Ilmu pendidikan Islami, 218.

35 'Abd Allah Nasih Ulwan dkk., Pendidikan Anak Dalam Islam, trans. oleh Jamaluddin Miri (Jakarta: Pustaka Amani, 2007), 321. 
Daruttaqwa sendiri KH. Munawwar, An Nafkhul Amim, Auliya `ul Falihin, Faidul Ilah dan juga beberapa kitab yang mengajarkah tentang akhlak. Mengenai pendidikan ahklak banyak di jelaskan secara terperinci dalam kitab Ta limul Mutaallim yaitu bab mengagungkan guru dan ilmu. Juga dalam kitab Ayyuhal walad yang menjelaskan tata karma kepada guru dalam menimba ilmu, bahkan di dalam kitab faidul Ilah karangan beliau sendiri ada bab khusus menjelaskan tata karma kepada guru, orang tua,ilmu dan orang-orang yang mencari ilmu. Kitab-kitab klasik tersebut menjadi kajian wajib bagi santri di pesantren Daruttaqwa, dan tentu saja di sertai pendalaman dan penghayatan terhadap isi kitab tersebut. Salah satu ahklak yang harus dimilik santri adalah sikap memuliakan guru dan rendah hati atau tidak takabbur serta berhidmah (melayani) kepada guru. Bagi santri di anjurkan untuk bersikap rendah hati dan berhidmah kepada gurunyaz6.

Hukuman dengan memukul adalah alternatif yang terakir yang diterapkan dalam Islam. Apabila nasihat dan teguran sudah tidak diindahkan oleh santri. Maka menjadi keharusan guru untuk tidak memperlakukan peserta didik secara kasar atau paksaan. Demikian pula sikap kasih sayang orang tua kepada anakanaknya. Kalupun harus terpaksa untuk menghukum santri hendaknya jangan memukul lebih dari tiga kali. Karena kekerasan bisa menjadi anak melakukan kebiasaan buruk 37 . Hukuman sering menimbulkan respon-respon yang tidak sesuai dengan perilaku yang diberi hukuman dan cukup kuat menekan perilaku tersebut 38. Yaitu dalam artian hanya bisa menekan akan tetapi tidak bisa merubah perilaku tersebut.

Mengingat dampak negatif yang ditimbulkan pemberian hukuman kepada anak didik, maka dalam pendidikan Islam ada ciri-ciri tertentu hukuman harus diberikan kepada peserta didik, seperti diungkapkan oleh Asma Hasan Fahmi. (1). Memberikan kesempatan kepada peserta didik untuk memperbaiki kesalahanya sebelum dipukul. Anak yang belum berusia 10 tahun

36 Al-Kurdi Muhammad Amiin, Tanwir Al Qulub fi Muamalat Allam AlGuyub, 5 ed. (Beirut Lebanon: Dar al-Kotob Al-Ilmiyah, 2010), 554.

37 Ibn Khaldūn, Muqoddimah Ibnu Khaldun, trans. oleh Thoha Ahmadie, 12 (Jakarta: Pustaka Firdaus, 2014), 763-64.

38 Dale H. Schunk, Learning theories: an educational perspective, 6 th ed (Boston: Pearson, 2012), 130. 
tidak boleh dipukul, kalaupun harus dipukul maka tidak boleh lebih dari tiga kali. (2). Hukuman diberikan untuk memperoleh perbaikan dan pengarahan. (3). Pendidik harus tegas dalam melaksanakan hukuman39.

Bagi pendidik yang ingin melakukan hukuman maka ini adalah Syarat-syarat menurut Ki Hajar Dewantara: (1) hukuman harus selaras dengan kesalahan anak (naturalistik) (2) hukuman harus dilakukan dengan adil (3) hukuman harus segara dijatuhkan. Walapun Ki Hajar Dewantara membolehkan hukuman akan tetapi hukuman harus paling terakir diberikan karena bisa menjadikan anak semakin menggagap remeh guru dan menjatuhkan wibawa guru 40 .

Pendidik harus mengedepankan rasa kasih sayang sehingga tidak harus menggunakan hukuman sebagai jawaban atas masalah anak apabila melakukan pelanggaran tata tertib pesantren. Dunia pesantren adalah dunia yang berbeda dengan pendidikan umum. Tradisi-tradisi hukuman hampir mengakar dalam tubuh pesantren hanya saja penerapan sekarang lebih humanis. Pendidik juga menganggap bahwa menghukum santri adalah suatu yang wajar karena itu adalah salah satu upaya agar anak tidak melakukan perbuatan pelanggaran tata tertib. Karena pendidik percaya bahwa hukuman bisa merubah perilaku santri yang kurang baik41.

\section{Batasan Hukuman di Pesantren}

Pesantren dalam menerapkan hukuman sebagai tindakan represif atas pelanggaran santri maka ada batasan-batasan yang harus dilakukan sehingga hukuman sebagai bentuk tujuan mendidik anak. Adapun persyaratannya adalah sebagai berikut:

1. Tidak terburu-buru menggunakan metode hukuman

2. Pendidik tidak boleh memukul ketika dalam keadaan marah

3. Ketika memukul hendaknya menghindari anggota badan yang peka, seperti kepala, muka, dada dan perut.

39 Ramayulis dan Nizar, Filsafat pendidikan Islam, 258.

40 Dewantara Hajar, Karya Ki Hajar Dewantara, 2 ed. (Yogyakarta: Majelis Luhur Persatuan Taman Siswa, 1977), 401.

41 Ahmadreza Fatahian Kelishadroky dkk., "The Role of Reward and Punishment in Learning," International Journal of Advanced Biotechnology and Research 7, no. special issue (1 Maret 2016): 783. 
4. Pukulan hendaknya tidak terlalu keras

5. Tidak memukul anak di bawah 10 tahun

6. Jika kesalahan pertama maka di tegur dan dinasehati saja.

7. Pendidik hendaknya memukul dengan tanganya sendiri

8. Jika berusia dewasa boleh, menghukum anak hingga jera tidak melakukan perbuatan pelanggaran lagi 42 .

Karena pendidik di pesantren awalnya adalah murid kyai juga sehingga bagaimanapun juga ustadz, pendidik mengidentifikasi kyai sebagai figur yang penuh karisma dan sebagai pengganti orang tua. Kyai adalah model uswah dari sikap dan tingkah laku warga pesantren. Proses sosialisasi dan interaksi yang berlangsung di pesantren memungkinkan warga pesantren melakukan imitasi terhadap sikap dan tingkah laku kyai sebagai figur ideal penyambung silsilah keilmuan para ulama' pewaris ilmu masa kejayaan Islam43..

Hal yang mendasar adalah kepatuhan santri terhadap kharismatik kyai sebagai pemegang otoritas. Hal ini memunculkan di kesadaran dalam diri santri bahwa hukuman yang diberikan kepadanya merupakan hukuman yang adil dan mendidik, sehingga dalam diri santri tidak mucul rasa dendam, namun sebaliknya justru memunculkan kesadaran memperbaiki diri dan kembali pada aturan aturan pesantren agar kelak mempunyai ilmu yang bermanfaat minimal seperti Kyainya.

Hukuman merupakan tindakan yang diperbolahkan dalam Islam dan itupun sudah diatur dan batasan-batasnya. Sedangkan kekerasan sama sekali tidak boleh dalam Islam. Kekerasan itu sama dengan perbuatan dhalim kepada seorang. Hukuman bisa menjadi kekerasan manakala sanksi yang diberikan bagi pelanggar secara berlebihan atau diluar batas kewajaran sehingga menyebabkan orang merasakan sakit secara fisik44.

\section{Simpulan}

Bentuk-bentuk pemberian hukuman bagi pelanggar tata tertib santri adalah dengan, teguran dan nasehat, hukuman administrasi,

42 Ulwan dkk., Pendidikan Anak Dalam Islam, 325-27.

43 Andurrahman Wahid dalam Zainuddin Syarif, "Mitos Nilai-Nilai Kepatuhan Santri," Tadris: Jurnal Pendidikan Islam 7, no. 1 (2013): 21.

44 M. Djamal, Fenomena Kekerasan, 369. 
hukuman yang mendidik, hukuman bersifat sosial, hukuman materi, hukuman bersifat fisik. Dari urutan hukuman tersebut hukuman fisik adalah cara yang paling akhir diberikan pada pelanggaran santri. Terdapat aturan bagi pendidik yang akan menerapkan hukuman antara lain tidak terburu-buru, tidak boleh memukul ketika dalam keadaan marah, hendaknya menghindari anggota badan yang peka, seperti kepala, muka, dada dan perut, pukulan hendaknya tidak terlalu keras, tidak memukul anak di bawah 10 tahun.. Sedangkan pada diri anak didik ditanamkan kesadaran dalam diri santri bahwa hukuman yang diberikan kepadanya merupakan hukuman yang adil dan mendidik.

\section{Daftar Referensi}

Baharuddin, 2007, Moh Makin, dan Abdul Qodir Shaleh. Pendidikan humanistik (konsep, teori, dan aplikasi praksis dalam dunia pendidikan). Yogyakarta: Ar-Ruzz Media.

Bogdan, Robert, dan Sari Knopp Biklen. 1998, Qualitative research for education: an introduction to theory and methods. 3rd ed. Boston: Allyn and Bacon.

Dhofier, Zamakhsyari, 2011, Tradisi pesantren: studi pandangan hidup kyai dan visinya mengenai masa depan Indonesia. Cet. 8 rev. Jakarta: LP3ES.

Dyah, Nawangsari. 2013, "Pemberian Hukuman Dalam Pendidikan Islam (Studi Makna Sanksi-Sanksi Pelanggaran Kode Etik Santri Di Pondok Pesantren Assunniyah Kencong Jember)." Disertasi, UIN Sunan Ampel Surabaya.

Engkus, Kuswarno, 2009, Metodelogi Penelitian Komunikasi, Fenomenologi, Konsepsi dan Pedoman. Bandung: Widya Padjadjaran.

Hajar, Dewantara, 1977, Karya Ki Hajar Dewantara. 2 ed. Yogyakarta: Majelis Luhur Persatuan Taman Siswa.

Hergenhahn, B. R, dan Matthew H Olson, 2016, Theories of learning = teori belajar. Diterjemahkan oleh Triwibowo. 6 ed. Jakarta: Prenada Media Grup.

Hiroko, Horikoshi, 1987, Kyai dan Perubahan Sosial. Diterjemahkan oleh Basalim Umar. Jakarta: P3M. 
Iqbal, Abu Muhammad, 2015, Pemikiran pendidikan Islam: gagasan-gagasan besar para ilmuwan Muslim. Cetakan 1. Yogyakarta: Pustaka Pelajar.

John W, Santrock, 2015, Psikologi Pendidikan. 2 ed. 6. Jakarta: Prenada Media Grup.

Kelishadroky, Ahmadreza Fatahian, Ali Shamsi, Mohmadreza Bagheri, BehrozShahmirzayi, dan Mojtaba Mansorihasanabadi. "The Role of Reward and Punishment in Learning." International Journal of Advanced Biotechnology and Research 7, no. special issue (1 Maret 2016): 780-88.

Khaldūn, Ibn, 2014, Muqoddimah Ibnu Khaldun. Diterjemahkan oleh Thoha Ahmadie. 12. Jakarta: Pustaka Firdaus.

Khosrow, Bagheri Naorapast, 2016, Pendidikan Islam, Wacana Alternatif. Diterjemahkan oleh Ety Triana. Jakarta: Citra.

Long, Martyn, ed, 2011, The Psychology of Education. 2nd ed. London; New York: Routledge.

M. Djamal, 2016, Fenomena Kekerasan di Sekolah. Yogyakarta: Pustaka Pelajar.

Malik, Fajar, 2005, Holistika Pemikiran Pendidikan. Jakarta: Raja Grafindo Persada.

Manfred, Ziemek 1983.Pesantren Dalam Perubahan Sosial. Jakarta: P3M.

Martin, Van Bruinessen, 2012,Kutab Kuning Pesantren dan Tarekat. 1 ed. Yogyakarta: Gading Publising.

—. 1992,Tarekat Naqsabandiyah DI Indonesia. $1 \mathrm{ed.}$ Bandung: Mizan.

Mastuhu, 1994, Dinamika sistem pendidikan pesantren: suatu kajian tentang unsur dan nilai sistem pendidikan pesantren. 2 ed. Jakarta: INIS.

Muhammad Amiin, 2010, Al-Kurdi. Tanwir Al Qulub fi Muamalat Allam Al-Guyub. 5 ed. Beirut Lebanon: Dar alKotob Al-Ilmiyah.

Ngalim, Purwanto, 2006, Ilmu Pendidikan Teoritis dan Praktis.

17 ed. Bandung: Remaja Rosdakarya.

Nurcholis, Madrid, 2016, Bilik-Bilik Pesantren Sebuah Potret Perjalanan. 6 ed. Jakarta: Paramadina Group. 
Qomar, Mujamil, 2012, Kesadaran Pendidikan, Sebuah Penentu Keberhasilan Pendidikan. Yogyakarta: Ar-Ruzz Media.

Ramayulis, dan Samsul Nizar, 2009, Filsafat pendidikan Islam: telaah sistem pendidikan dan pemikiran para tokohnya. Jakarta: Kalam Mulia.

Ridlwan, Nair, 2010, Mencari Tipologi Format Pendidikan Ideal di Tengah Arus Perubahan. 2 ed. Jakarta: Pustaka Pelajar.

Schunk, Dale H, 2012, Learning theories: an educational perspective. 6th ed. Boston: Pearson.

Suprayogo, Imam, 2013, Pengembangan pendidikan karakter. Malang: UIN Maliki Press.

Syarif, Zainuddin. "Mitos Nilai-Nilai Kepatuhan Santri.” Tadris: Jurnal Pendidikan Islam 7, no. 1 (2013): 19-30.

Tafsir, Ahmad, 992, Ilmu pendidikan dalam perspektif Islam. Cet. 1. Bandung: Remaja Rosdakarya, 1.

_ 2012, Ilmu pendidikan Islami. Cet. 1. Bandung: Remaja Rosdakarya.

Ulwan, 'Abd Allah Nasih, Muhammad Kamal al-Din 'Abd alGhani, Muhammad al-Shahhat Jindi, 'Ali 'Ali Ahmad Sha'ban, Muhammad Mahmud Ghali, dan Ahmad Shafiq Khatib, 2007, Pendidikan Anak Dalam Islam. Diterjemahkan oleh Jamaluddin Miri. Jakarta: Pustaka Amani.

Wong Pail, 2011, " Corporal Punishment of Students by Teachers in Elementary and Middle Schools in Taiwan the Relationship with School Level, Gender, School Location, Academic Performance and Emotional Reactions." Dissertation, University of Southern California.

Zaprulkan, 2006, Ilmu Tasawuf Sebuah Kajian Tematik. Jakarta: Raja Grafindo Persada. 